\title{
KONDISI HIPOKSIA DAN LAJU DEKOMPOSISI BAHAN ORGANIK DI LOKASI BUDIDAYA IKAN WADUK IR. H. DJUANDA
}

\section{HYPOXIA CONDITION AND RATE OF ORGANIC MATTER DECOMPOSITION IN AREA OF FISH CULTURE AT IR. H. DJUANDA RESERVOIR}

\author{
Lismining Pujiyani Astuti', Enan Mulyana Adiwilaga ${ }^{2}$, Budi Indra Setiawan ${ }^{3}$, Niken Tunjung Murti Pratiwi² \\ ${ }^{1}$ Mahasiswa pada Pasca Sarjana Institut Pertanian Bogor-IPB \\ ${ }^{2}$ Dosen pada Fakultas Perikanan dan ilmu Kelautan Institut Pertanian Bogor-IPB \\ ${ }^{3}$ Dosen pada Fakultas Keteknikan Pertanian Institut Pertanian Bogor-IPB \\ Teregistrasi I tanggal: 10 September 2014; Diterima setelah perbaikan tanggal: 26 November 2014; \\ Disetujui terbit tanggal: 26 November 2014 \\ Email: lisminingastuti@gmail.com
}

\begin{abstract}
ABSTRAK
Waduk Ir. H. Djuanda merupakan waduk multi fungsi yang salah satunya adalah untuk kegiatan budidaya ikan. Adanya input pakan dari kegiatan budidaya dapat menyebabkan peningkatan bahan organik dan penurunan konsentrasi oksigen terlarut. Kegiatan budidaya ikan dalam karamba jaring apung (KJA) menyumbang bahan organik ke perairan yang laju dekomposisinya (k) (per hari) dipengaruhi oleh suhu perairan. Tujuan penelitian ini untuk mengetahui kedalaman hipoksia di lokasi karamba jaring apung untuk budidaya ikan di Waduk Ir. H. Djuanda dan pengaruh suhu terhadap besarnya laju dekomposisi bahan organik (k). Penelitian kondisi hipoksia dilakukan di Waduk Ir. H Djuanda dan selanjutnya pengamatan BOD untuk penentuan laju dekomposisi bahan organik di Laboratorium Balai Penelitian Pemulihan dan Konservasi Sumberdaya Ikan pada bulan FebruariApril 2013. Penentuan kondisi hipoksia berdasaran Peraturan Pemerintah Republik Indonesia Nomor 82 Tahun 2001 dan penentuan laju dekomposisi berdasarkan Least Square Method. Hasil penelitian menunjukkan bahwa kedalaman hipoksia dimulai pada kedalaman $3 \mathrm{~m}$ dan laju dekomposisi bahan organik $(k)$ tertinggi pada suhu $28,5^{\circ} \mathrm{C}$ yaitu sebesar $0,189 /$ hari.
\end{abstract}

KATA KUNCI: Laju dekomposisi, hipoksia, bahan organik, suhu, Waduk Ir. H. Djuanda

\begin{abstract}
Ir H. Djuanda Reservoir is a multi-purpose reservoirs, one of which is for fisheries culture activity. Feed inputs from aquaculture activities can lead to an increase in organic matter and a decrease in dissolved oxygen concentration. Cultivation of fish in floating cage net contributing organic material into waters which the rate of organic matter decomposition ( $k$ ) (per day) is affected by water temperature. The purpose of this study was to know the depth of hypoxia in floating cage net for fisheries culture in the Ir. H. Djuanda Reservoir and the effect of temperature on the amount of organic matter decomposition rates $(k)$. Observation of hypoxic conditions was conducted in Ir. H Djuanda Reservoir and furthermore observation of BOD to determine the rate of organic matter decomposition at Research Institute for Rehabilitation and Conservation of Fish Resources laboratory in February-April, 2013. Determination of hypoxic conditions based on Government Regulation of the Republic Indonesia Number 81 Year 2001 and the determination of the rate of decomposition based on Least Square Method. The results showed that the depth of hypoxia began at a depth of $3 \mathrm{~m}$ and the higher of decomposition rate of organic matter $(k)$ was $0.189 /$ day at temperature $28.5^{\circ} \mathrm{C}$.
\end{abstract}

KEYWORDS: Decomposition rate, hypoxia, organic matter, temperature, Ir. H. Juanda

\section{PENDAHULUAN}

Menurut Azwar et al. (2004), teknologi budidaya ikan dalam karamba jaring apung (kja) merupakan salah satu paket teknologi yang cocok untuk diterapkan di perairan umum khususnya perairan danau dan waduk. Pada tahun 2000, jumlah kja adalah 2537 petak dengan produksi ikan sebesar 3791,1 ton dan pada tahun 2010, jumlah kja mencapai 19630 petak dengan produksi ikan sebesar 71095,96 ton (Dinas Peternakan dan Perikanan Kabupaten Purwakarta, 2011). Dalam kurun waktu 10 tahun terjadi peningkatan produksi ikan sebesar 67304,86 ton. Sistem budidaya ini merupakan sistem budidaya secara intensif dengan pemberian pakan ikan sebagai input energi untuk pertumbuhan ikan. Tidak semua pakan yang diberikan pada ikan dapat dimanfaatkan karena keterbatasan kemampuan ikan. Sebagian pakan akan terbuang ke lingkungan perairan dapat menyebabkan pengkayaan nutrien yang berpotensi pada perubahan kualitas air (Azwar et al., 2004, Simarmata, 2007). Mc Donad et al. (1996) menyatakan bahwa 30\% dari jumlah pakan yang diberikan tertinggal sebagai pakan yang tidak dikonsumsi dan 25-30\% dari pakan yang dikonsumsi akan diekskresikan. Sementara menurut Krismono (1992) pakan

Korespondensi penulis:

Pasca Sarjana Institut Pertanian Bogor-IPB

Jl. Raya Darmaga Kampus IPB Darmaga Bogor-16680 
ikan yang terbuang pada KJA ukuran $7 \times 7 \times 3 \mathrm{~m}^{3}$ adalah 20\%-30\% dan untuk ukuran $1 \times 1 \times 1 \mathrm{~m}^{3}$ sebanyak 30\%-50\%. Selanjutnya Barg (1992) menyatakan partikel bahan organik akan mengendap disekitar lokasi KJA jika kecepatan pengendapan partikel jauh lebih besar dari pada kecepatan arus.

Usaha budidaya ikan dalam KJA di Waduk Ir. H. Djuanda dari tahun ke tahun terus mengalami peningkatan. Berdasarkan SK Bupati Purwakarta No 06 Tahun 2000, jumlah KJA yang optimum adalah 2.100 petak. Ternyata sampai akhir tahun 2010 telah mencapai 19.630 (Dinas Peternakan dan Perikanan Kabupaten Purwakarta, 2011) atau sembilan kali lipat lebih dari kapasitas yang diijinkan. Apabila semua KJA aktif digunakan maka jumlah pakan dan biomassa ikan yang dibudidayakan juga meningkat sehingga bahan pencemar berupa sisa pakan yang terbuang dan feses ikan akan meningkat pula yang akhirnya dapat berdampak pada perubahan kualitas air termasuk oksigen perairan.

Oksigen sangat penting dalam proses respirasi untuk sebagian besar biota akuatik. Dinamika oksigen terlarut tergantung pada input dari atmosfer dan proses fotosintesis dan hilang melalui oksidasi kimia dan biologi. Distribusi oksigen penting karena diperlukan oleh fauna akuatik dan mempengaruhi ketersediaan beberapa nutrien yang selanjutnya mempengaruhi produktivitas perairan (Wetzel, 2001). Oksigen terlarut (dissolved oxygen (DO) merupakan salah satu faktor yang menentukan bagi kehidupan ikan dan organisme perairan lainnya. Menurut Buttner \& Soderberg (1993) untuk kegiatan budidaya dan kehidupan ikan memerlukan konsentrasi oksigen $>3 \mathrm{mg} / \mathrm{L}$ dan berdasarkan Peraturan Pemerintah Republik Indonesia Nomor 82 Tahun 2001, oksigen terlarut untuk kegiatan perikanan minimal $3 \mathrm{mg} / \mathrm{L}$. Sementara menurut Toufeek \& Korium (2009) konsentrasi oksigen bebas < 2 $\mathrm{mg} / \mathrm{l}$ untuk beberapa hari dapat mematikan ikan dan organisme akuatik lainnya, sementara oksigen yang baik untuk populasi ikan adalah $5-6 \mathrm{mg} / \mathrm{l} /$.

Peningkatan sisa pakan yang terbuang dan feses ikan dapat menyebabkan peningkatan bahan organik perairan. Peningkatan bahan organik perairan dapat menyebabkan penurunan oksigen pada lapisan bawah permukaan karena oksigen dimanfaatkan untuk respirasi biota akuatik dan proses dekomposisi bahan organik sehingga lapisan oksik menipis akibatnya pada kedalaman tertentu terjadi kondisi hipoksia. Kondisi hipoksia merupakan hasil dari ketidakseimbangan antara produksi biologi dan konsumsi oksigen (Pena et al., 2010). Kondisi hipoksia merupakan salah satu permasalahan di perairan air tawar karena dapat menyebabkan stress biota atau bahkan kematian biota akuatik, bau, dan gangguan estetika lainnya (Schierholz et al., 2006; Desa et al., 2009)
Biochemical Oxygen Demand (BOD) adalah banyaknya oksigen yang diperlukan oleh mikroorganisme untuk mendekomposisi bahan organik. Nilai BOD dipengaruhi oleh suhu, $\mathrm{pH}$, waktu inkubasi, kondisi osmotik, serta ketersediaan oksigen (Dhage et al., 2012). Nilai $k$ (konstanta laju BOD) menunjukkan besarnya laju penguraian bahan organik oleh mikroorganisme aerob perairan dan nilai $k$ pada kondisi aerobik adalah $1 /$ hari (Astono et.al., 2008; Harsono, 2010). BOD ultimat adalah jumlah total oksigen yang dikonsumsi selama reaksi (Dhage et al., 2012). Tujuan penelitian ini untuk mengetahui kedalaman hipoksia di lokasi karamba jaring apung untuk budidaya ikan di Waduk Ir. H. Djuanda dan pengaruh suhu terhadap besarnya laju dekomposisi bahan $\operatorname{organik}(k)$.

\section{BAHANDANMETODE}

Penelitian ini dilakukan pada bulan Februari - April 2013 pada salah satu KJA di Waduk Ir. H. Djuanda, Purwakarta (Gambar. 1.). Penentuan kedalaman hipoksia dengan pengukuran konsentrasi oksigen, secara vertikal setiap meternya dari permukaan hingga kedalaman maksimal dari karamba yaitu permukaan, 1, 2, 3 dan 4 m. Pengukuran oksigen terlarut menggunakan alat Water Quality Checker merk YSI 55. Berdasarkan Peraturan Pemerintah Republik Indonesia Nomor 82 Tahun 2001 menyatakan bahwa oksigen untuk kegiatan perikanan adalah > $3 \mathrm{mg} / \mathrm{l}$ sehingga kondisi hipoksia apabila konsentrasi oksigen $<3 \mathrm{mg} / 1$.

Selanjutnya pada kedalaman hipoksia diambil sampel air untuk pengukuran BOD dalam rangka penentuan laju dekomposisi bahan organik. Sampel untuk BOD diambil berdasarkan hasil monitoring kondisi hipoksia pada bulan Februari (pengamatan 1) dan April (pengamatan 3). Penentuan laju dekomposisi bahan organik melalui pengukuran BOD dilakukan di laboratorium kualitas air Balai Penelitian Pemulihan dan Konservasi Sumberdaya Ikan. Sampel air yang diambil sebanyak 3 L kemudian diaerasi selama 2 jam yang bertujuan agar selama tujuh hari pengamatan tidak kehabisan oksigen dan selanjutnya dimasukkan ke dalam botol winkler gelap sebanyak 8 botol. Pengamatan BOD melalui pengamatan oksigen terlarut setiap hari dengan metode Winkler. Oksigen hari 0 di ukur sebagai DO awal kemudian sampel yang lain diinkubasi sesuai dengan hasil pengamatan suhu lapangan dan setiap hari diukur DO-nya. Suhu inkubasi di inkubator disesuaikan dengan suhu kedalaman hipoksia di lapangan yaitu suhu 27 dan $28,5^{\circ} \mathrm{C}$. Perlakuan suhu yang lebih rendah dari suhu lapangan adalah $20^{\circ} \mathrm{C}$, sedangkan $30^{\circ} \mathrm{C}$ merupakan suhu yang lebih tinggi dari kondisi lapangan. Perlakuan inkubasi suhu 28,5 dan $20^{\circ} \mathrm{C}$ (pengamatan 1) merupakan hasil pengamatan kondisi hipoksia bulan Februari dan pengamatan 2 dengan suhu 27 dan $30^{\circ} \mathrm{C}$ yang 


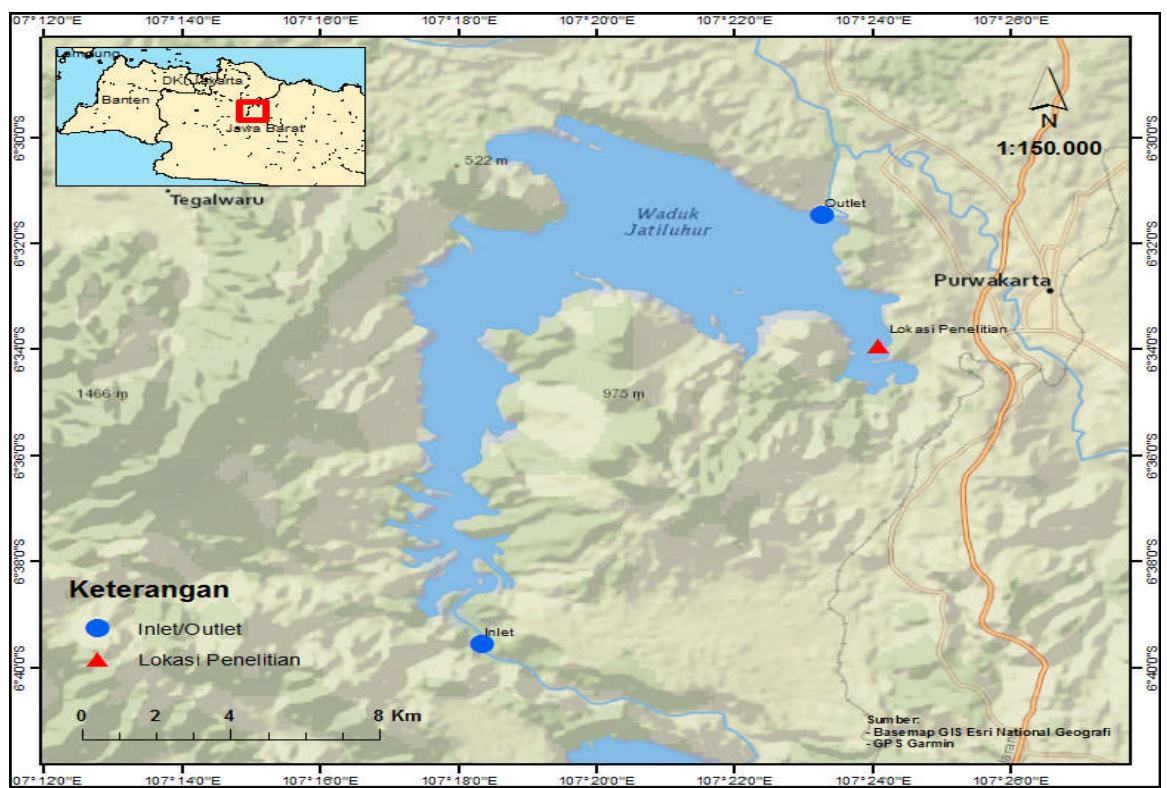

Gambar 1. Lokasi penelitian di Waduk Ir. H. Djuanda.

Figure 1. Research site at Ir. H. Djuanda Reservoir.

merupakan hasil pengamatan kondisi hipoksia bulan April. Pengamatan BOD dilakukan setiap hari selama 7 hari seperti penelitian Singh (2004). Perhitungan nilai BOD adalah:

$$
\mathrm{BOD}_{\mathrm{t}}=\left[\mathrm{DO}_{0 \text { hari }}-\mathrm{DO}_{\mathrm{t}}\right]
$$

Untuk menentukan nilai laju oksidasi berdasarkan hasil pengamatan BOD harian berdasarkan Least square method (Tchobanoglous et al., 2003; Singh, 2004)) yaitu:

$$
\mathrm{dL} / \mathrm{dt}=-\mathrm{kL}_{\mathrm{t}}
$$

dimana:

$$
\begin{aligned}
& \mathrm{L}_{\mathrm{t}}=\mathrm{L}_{0}-\mathrm{y}_{\mathrm{t}} \\
& \mathrm{y}_{\mathrm{t}}=\mathrm{BOD}_{\mathrm{t}} \\
& \mathrm{dy} / \mathrm{dt}=\mathrm{k}\left(\mathrm{L}_{0}-\mathrm{y}_{\mathrm{t}}\right) \\
& \mathrm{dy} / \mathrm{dt}=\mathrm{kL}_{0}-\mathrm{ky}_{\mathrm{t}}
\end{aligned}
$$

penentuan nilai $k$ dan $\mathrm{L}_{0}$ berdasarkan persamaan linear sehingga dapat dihitung :

$$
\begin{aligned}
& \mathrm{S}_{\mathrm{xx}}=\mathrm{n} \sum \mathrm{y}_{\mathrm{t}}^{2}-\left(\sum \mathrm{y}\right)^{2} \\
& \mathrm{~S}_{\mathrm{xy}}=\mathrm{n} \sum \mathrm{y}_{\mathrm{t}}(\mathrm{dy} / \mathrm{dt})-\left(\sum \mathrm{y}_{\mathrm{t}}\right)\left(\sum \mathrm{dy} / \mathrm{dt}\right)
\end{aligned}
$$

Slope atau $-\mathrm{k}=\mathrm{S}_{\mathrm{xy}} / \mathrm{S}_{\mathrm{xx}}$

Intersep atau $\mathrm{kL}_{0}=\sum(\mathrm{dy} / \mathrm{dt}) / \mathrm{n}+\mathrm{k} \sum\left(\mathrm{y}_{\mathrm{t}}\right) / \mathrm{n}$

$\mathrm{L}_{0}=$ Intersep / (-slope)

$\mathrm{dy} / \mathrm{dt}=\left(\mathrm{y}_{\mathrm{t}+1}-\mathrm{y}_{\mathrm{t}-1}\right) / 2 \Delta \mathrm{t}$

$\mathrm{y}_{\mathrm{t}}$ : nilai BOD hasil pengamatan $(\mathrm{mg} / \mathrm{l})$

$\mathrm{y}_{0}:$ BOD awal atau hari ke 0

"t : waktu selang pengamatan

$\mathrm{T}$ : pengamatan hari ke $1,2,3, \ldots$

$\mathrm{L}_{0} \quad$ : BOD ultimat (mg/l) n : Jumlah total pengamatan

$K \quad$ : Laju reaksi (per hari)

Sehingga dapat dibuat tabel pengamatan

\begin{tabular}{lllll}
\hline Hari/Day & $\mathbf{y}_{\mathbf{t}}$ & $\mathbf{d y} / \mathbf{d t}$ & $\mathbf{y}_{\mathbf{t}}{ }^{2}$ & $\mathbf{y}_{\mathbf{t}} \cdot \mathbf{d y} / \mathbf{d t}$ \\
\hline 1 & & & & \\
2 & & & & \\
3 & & & & \\
4 & & & & \\
5 & & & & \\
6 & & & & \\
Total & & & & \\
\hline
\end{tabular}

\section{HASIL DAN BAHASAN}

\section{HASIL}

Hasil monitoring kondisi hipoksia di lokasi budidaya ikan dalam karamba di Waduk Ir. H. Djuanda disajikan pada Gambar 2. Pengamatan satu merupakan hasil monitoring bulan Februari, pengamatan dua hasil monitoring bulan Maret dan pengamatan tiga adalah hasil monitoring bulan April.

Gambar 2. menunjukkan bahwa profil oksigen selama pengamatan pada permukaan oksigen tinggi dan menurun sejalan dengan meningkatnya kedalaman perairan. Kedalaman hipoksia pada pengamatan 1, 2, dan 3 berturut turut 4; 4 dan 3 m di dalam karamba. Kedalaman hipoksia berfluktuasi, terutama pada saat pengamatan 2 yaitu cuaca yang berangin kencang mengakibatkan gelombang dan mempercepat proses reaerasi sehingga meningkatkan oksigen perairan. Sesuai dengan pengamatan 3 di bulan 


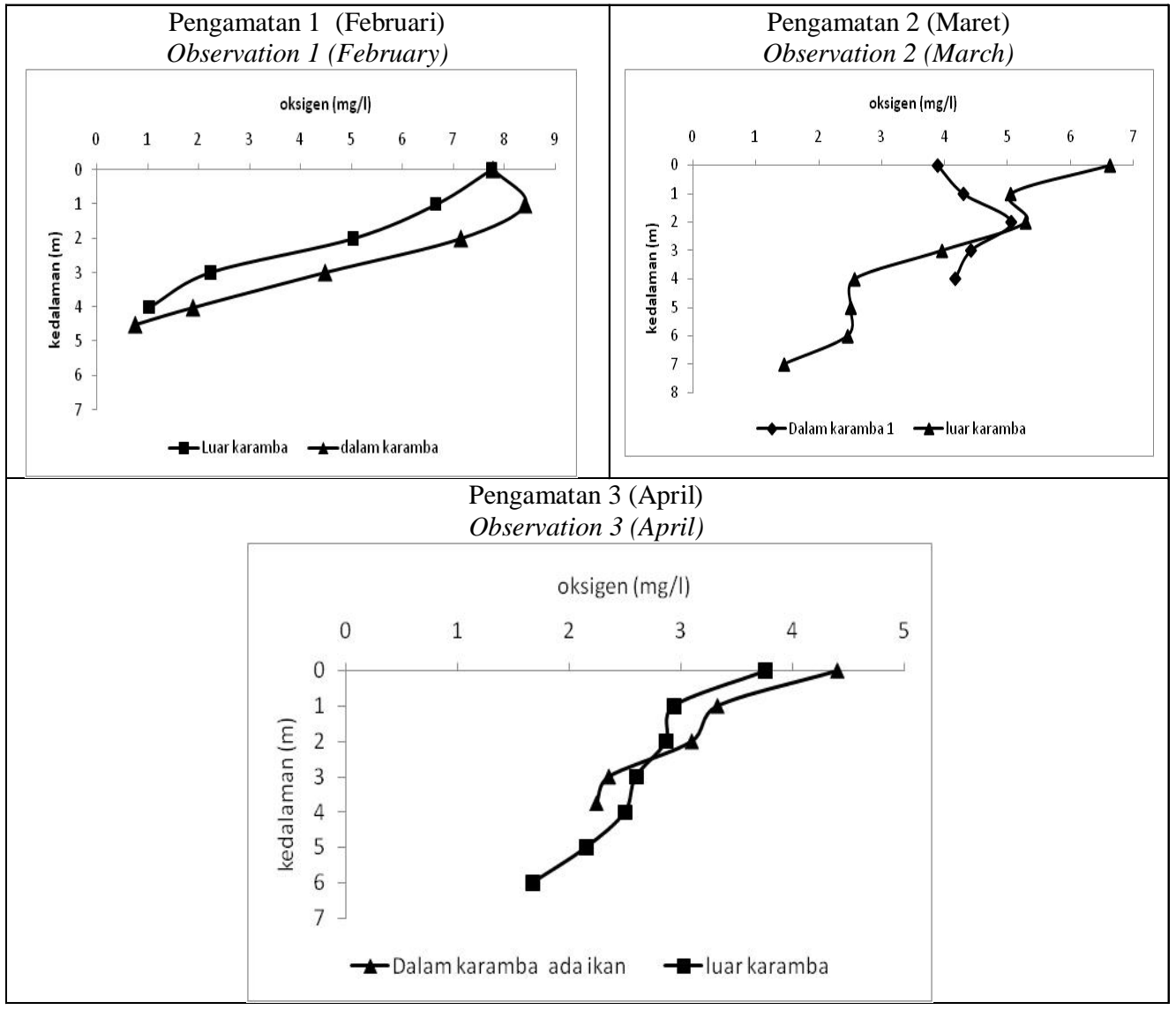

Gambar 2. Profil oksigen terlarut perairan secara vertical.

Figure 2. Vertical profile of oxygen dissolved in waters.

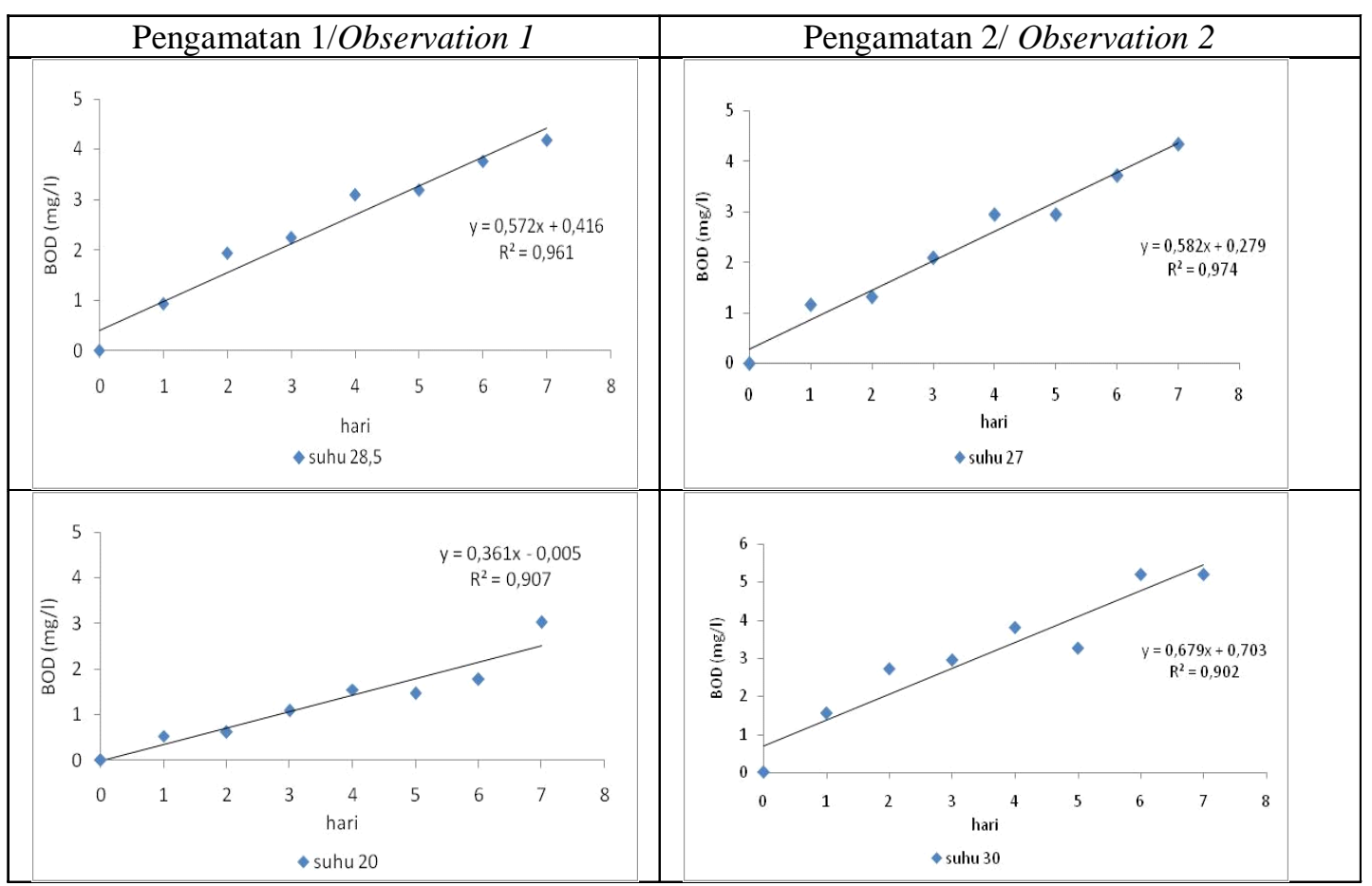

Gambar 3. Pengamatan BOD setiap hari berdasarkan suhu inkubasi selama 7 hari.

Figure 3. Observation of BOD based on daily temperature of incubation during for 7 days. 
Tabel 1. Nilai $\mathrm{BOD}_{5}$, laju dekomposisi bahan organic $(k)$ dan BOD ultimat (Lo) dari sampel air waduk berdasarkan perlakuan suhu yang berbeda

Table 1. $B_{3}$, rate of organic matter decomposition $(k)$ and BOD ultimate (Lo) value from sample of water reservoir based on difference of temperature treatment

\begin{tabular}{|c|c|c|c|c|}
\hline \multirow{2}{*}{$\begin{array}{l}\text { Parameter } \\
\text { (Parameters) }\end{array}$} & \multicolumn{2}{|c|}{ Penelitian 1 (first research) } & \multicolumn{2}{|c|}{ Penelitian 2 (Second research) } \\
\hline & $20^{\circ} \mathrm{C}$ & $28,5^{\circ} \mathrm{C}^{*}$ & $27^{*}$ & $30^{\circ} \mathrm{C}$ \\
\hline $\mathrm{BOD}_{5}(\mathrm{mg} / \mathrm{l})$ & 1,47 & 3,19 & 2,95 & 3,26 \\
\hline$k$ (per hari) & 0,141 & 0,189 & 0,016 & 0,114 \\
\hline Lo $(\mathrm{mg} / \mathrm{l})$ & 3,69 & 5,64 & 37,27 & 9,67 \\
\hline
\end{tabular}

*Suhu sesuai dengan pengamatan di lapangan

April 2013 maka kedalaman hipoksia dimulai pada kedalaman $3 \mathrm{~m}$ ke bawah.

Hubungan antara waktu dan nilai BOD sangat erat yang ditunjukkan dengan nilai $\mathrm{R}$ mendekati 1 pada semua pengamatan. Hubungan antara nilai BOD dan waktu inkubasi pada suhu $20^{\circ} \mathrm{C}$ adalah $\mathrm{y}=0,361 \mathrm{x}-0,005$ dengan $\mathrm{R}^{2}=0,907$; suhu $28,5^{\circ} \mathrm{C}$ adalah $\mathrm{y}=0,572 \mathrm{x}+0,416$ dengan $\mathrm{R}^{2}=0,961$; suhu $30^{\circ} \mathrm{C}$ adalah $\mathrm{y}=0,679 \mathrm{x}+0,703$ dengan $\mathrm{R}^{2}$ $=0,902 ;$ suhu $27^{\circ} \mathrm{C}$ adalah $\mathrm{y}=0,582 \mathrm{x}+0,279$ dengan $\mathrm{R}^{2}=$ 0,974 (Gambar 3).

Hasil pengamatan $\mathrm{BOD}_{5}$, laju dekomposisi bahan organik $(k)$ dan BOD ultimat (Lo) dari perlakuan suhu inkubasi disajikan pada Tabel 1.

Berdasarkan hasil pengamatan (Tabel 1) menunjukkan bahwa laju dekomposisi bahan organik $(k)$ pada suhu $28,5^{\circ} \mathrm{C}$ lebih tinggi dibanding suhu $20^{\circ} \mathrm{C}$ dan juga pada suhu $30^{\circ} \mathrm{C}$ lebih tinggi dibanding suhu $27^{\circ} \mathrm{C}$.

\section{BAHASAN}

\section{Kedalaman Hipoksia}

Hasil penelitian Simarmata (2007) menyebutkan bahwa kedalaman lapisan oksik di zona transisi yaitu daerah sekitar kegiatan KJA di Waduk Ir.H.Djuanda pada musim kemarau berkisar $0,66-1,77 \mathrm{~m}$; pada musim peralihan 1,92$2,56 \mathrm{~m}$ dan pada musim penghujan $6,08-7,55 \mathrm{~m}$. Pada pengamatan bulan April (Gambar 2), konsentrasi oksigen terlarut adalah $<3 \mathrm{mg} / \mathrm{l}$ dimulai pada kedalaman $3 \mathrm{~m}$ ke bawah atau lapisan oksik pada kedalaman $3 \mathrm{~m}$ ke atas berarti kedalaman hipoksia lebih dalam atau lapisan oksik lebih tebal dibandingkan pada musim kemarau dan musim peralihan namun lebih dangkal atau lapisan oksik lebih tipis dibandingkan musim penghujan. Konsentrasi oksigen di waduk dataran rendah di India paling tinggi di permukaan hingga kedalaman $5 \mathrm{~m}$ kemudian menurun secara cepat hingga kedalaman $21 \mathrm{~m}$ (Desa et al., 2009).

Pada permukaan, konsentrasi oksigen lebih tinggi karena adanya pertukaran oksigen atmosfer dan lapisan epilimnion dan hasil fotosintesis alga. Menurunnya oksigen pada lapisan di bawah epilimnion karena digunakan untuk respirasi (Salmin, 2005; Desa et al., 2009). Dengan bertambahnya kedalaman akan terjadi penurunan kadar oksigen terlarut, karena proses fotosintesis semakin berkurang dan kadar oksigen yang ada banyak digunakan untuk respirasi biota akuatik dan dekomposisi bahanbahan organik dan anorganik. Ketersediaan oksigen pada lapisan hipolimnion sangat penting untuk proses oksidasi serta penting bagi organisme yang hidup pada lapisan tersebut. Pada lapisan hipolimnion, konsentrasi oksigen terlarut akan semakin sedikit atau bahkan tidak ada oksigen (anoksik) karena oksigen telah dimanfaatkan untuk proses dekomposisi bahan organik dan proses respirasi

\section{Laju Dekomposisi Bahan Organik}

Berdasarkan Gambar 3 menunjukkan bahwa semakin lama waktu inkubasi maka semakin besar nilai BOD. Hal ini karena ketersediaan oksigen yang menipis sementara masih ada bahan organik yang belum terdekomposisi serta adanya sebagian bakteri aerob yang mati karena ketersediaan oksigen tidak mencukupi untuk kehidupannya, akibatnya bakteri tersebut menjadi salah satu sumber yang meningkatkan bahan organik.

Berdasarkan Tabel 1. menunjukkan pada pengamatan pertama, laju dekomposisi bahan organik yang diinkubasi pada suhu 28,5 p C yaitu $0,189 /$ hari lebih besar dibandingkan yang diinkubasi pada suhu $20 \mathrm{p} \mathrm{C}$ yaitu $0,141 /$ hari. Demikian juga pada pengamatan kedua menunjukkan bahwa laju dekomposisi bahan organik yang diinkubasi pada suhu $30 \mathrm{p} \mathrm{C}$ yaitu sebesar $0,114 /$ hari lebih besar dibandingkan yang ddinkubasi pada suhu 27 p C yaitu $0,016 /$ hari. Berdasarkan kedua pengamatan menunjukkan bahwa suhu 28,5 p C mempunyai laju dekomposisi bahan organik tertinggi. Menurut Simarmata et al, (2008), laju dekomposisi bahan organik di zona budidaya ikan Waduk Jatiluhur adalah $0,03-0,015$ /hari. Hasil pengamatan penelitian ini adalah 0,016 /hari dan 0,189 /hari yang artinya ada peningkatan laju dekomposisi bahan organik dibandingkan penelitian sebelumnya oleh Simarmata (2007). Pengamatan laju dekomposisi sedimen dasar kolam budidaya ikan adalah 0,4/tahun (Avnimelech et al., 1995). Hasil penelitian Dhage et al. (2012), nilai $k$ 
Tabel 2. Laju dekomposisi bahan organik ( $k$ ) (per hari) untuk limbah rumah potong hewan, limbah tekstil dan air Sungai Ciliwung yang diinkubasi pada beberapa suhu

Table 2. $\quad$ Rate of organic matter decomposition ( $k$ ) (per day) for abattoir waste water, textile waste water and water from Ciliwung River at some temperatures of incubation

\begin{tabular}{l|c|c|c}
\hline \multirow{2}{*}{$\begin{array}{c}\text { Jenis limbah } \\
\text { (Waste water) }\end{array}$} & \multicolumn{3}{c}{ Suhu (Temperature) } \\
\cline { 2 - 4 } & $\mathbf{2 0}^{\circ} \mathbf{C}$ & $\mathbf{2 5}^{\circ} \mathbf{C}$ & $\mathbf{3 0}^{\circ} \mathbf{C}$ \\
\hline Rumah potong hewan (Abattoir) & 0,151 & 0,196 & 0,283 \\
Limbah tekstil (Textile) & 0,128 & 0,149 & 0,233 \\
Air Sungai Ciliwung (Ciliwung River) & 0,123 & 0,183 & 0,228 \\
\hline
\end{tabular}

Sumber/Source: Polli (1994)

Tabel 3. Nilai BOD ultimat (Lo) (mg/l) untuk limbah rumah potong hewan, limbah tekstil dan air Sungai Ciliwung yang diinkubasi pada beberapa suhu.

Table 3. BOD ultimate (Lo) ( $\mathrm{mg} / \mathrm{l})$ value for abattoir waste water, textile waste water and water from Ciliwung River at some temperatures of incubation

\begin{tabular}{l|c|c|c}
\hline \multirow{2}{c}{$\begin{array}{c}\text { Jenis limbah } \\
\text { (Waste water) }\end{array}$} & \multicolumn{3}{c}{ Suhu (Temperatures) } \\
\hline & $20^{\circ} \mathrm{C}$ & $25^{\circ} \mathrm{C}$ & $30^{\circ} \mathrm{C}$ \\
\hline Rumah potong hewan (Abattoir) & 6,441 & 6,483 & 6,365 \\
Limbah tekstil (Textile) & 7,772 & 7,498 & 7,431 \\
Air Sungai Ciliwung (Ciliwung River) & 6,374 & 7,110 & 13,245 \\
\hline
\end{tabular}

\section{Sumber/Source: Polli (1994)}

untuk limbah domestik lebih tinggi pada suhu inkubasi 27 ${ }^{\circ} \mathrm{C}(0,2-0,3$ per hari $)$ dibanding suhu $20^{\circ} \mathrm{C}(0,12-0,2$ per hari). Hasil penelitian Polli (1994) menunjukkan bahwa nilai $k$ pada suhu $30{ }^{\circ} \mathrm{C}$ lebih tinggi dibandingkan suhu $20^{\circ} \mathrm{C}$ dan $25^{\circ} \mathrm{C}$ seperti pada Tabel 2.

Suhu dapat mempengaruhi reaksi oksidasi karena mempengaruhi kinerja enzim-enzim pada mikroorganisme pengoksidasi. Hasil pengamatan laju dekomposisi pada danau di Hanoi yang tercemar oleh bahan organik adalah 0,93/hari (Thang et al., 2005). Laju dekomposisi dipengaruhi oleh suhu dan oksigen, serta dipengaruhi pula oleh komposisi penyusun bahan organik seperti gula, selulosa atau lignin. Laju dekomposisi gula, hemiselulosa, selulosa, dan lignin adalah berbeda-beda dan secara berurutan adalah 1,15;0,1;0,05 dan 0,002/hari (Avnimelech et al., 1995).

Nilai BOD ultimat pada inkubasi suhu $28,5^{\circ} \mathrm{C}$ adalah $10,29 \mathrm{mg} / \mathrm{l}$ sementara pada inkubasi suhu $30^{\circ} \mathrm{C}$ adalah 11 , 53 mg/l. Menurut Peavy et al. (1984) dalam Polli (1994) menyatakan bahwa nilai $k$ menentukan kecepatan reaksi BOD tanpa mempengaruhi besaran nilai BOD ultimat. Hal tersebut sesuai dengan hasil penelitian ini (Tabel 2) dan penelitian Polli (1994) (Tabel 3.)

\section{KESIMPULAN}

Kedalaman hipoksia di lokasi budidaya ikan Waduk Ir. H. Djuanda dimulai pada kedalaman $3 \mathrm{~m}$.
Nilai laju dekomposisi bahan organik $(k)$ pada lokasi budidaya ikan dalam karamba tertinggi adalah pada suhu $28,5^{\circ} \mathrm{C}$ yaitu sebesar 0,189 per hari.

\section{SARAN}

Perlu dilakukan monitoring kualitas air secara kontinyu terutama oksigen terlarut agar terpantau kedalaman lapisan oksigennya dan permulaan kedalaman hipoksia terutama di lokasi budidaya sebagai early warning terhadap kemungkinan kejadian kematian ikan karena konsentrasi oksigen yang rendah. Untuk menghindari terjadinya kondisi kritis oksigen dapat dilakukan melalui peningkatan oksigen terlarut seperti dengan teknik aerasi lapisan hipoksia.

\section{DAFTAR PUSTAKA}

Astono, W., M.S. Saeni., B.W. Lay \& S. Soemarto. 2008. Pengembangan model DO - BOD dalam pengelolaan kualitas air Sungai Ciliwung. Forum Pascasarjana. 31 (1) : 37-45.

Avnimelech,Y., N. Mozes, S. Diab \& M. Kochba. 1995. Rate of organik carbon and nitrogen degradation in intensive fish pond. Aquaculture. 134: 211-216.

Azwar, Z.I., N. Suhenda \& O. Praseno. 2004. Manajemen pakan pada usaha budidaya ikan dalam karamba jaring apung. Prosiding Pengembangan Budidaya 
Perikanan di Perairan Waduk. Pusat Riset Perikanan Budidaya, Jakarta: p 37 - 44 .

Barg, UC. 1992. Guidelines for the Promotion of Environmental Management of Coastal Aquaculture Development. FAO Fisheries Technical Paper 328, FAO, Rome. p 122.

Buttner, J.K \& R.W. Soderberg. 1993. An Introduction to Water Chemistry in Freshwater Aquaculture. NRAC Fact Sheet No. 170. University of Massachusetts: $12 \mathrm{hlm}$.

Desa, E., R.Madhan, P.Maurya, G. Navelker, A. Mascerontias, S. Prabhudesai, S.A. Afzulpurkar, A. pascoal \& Nambiar. 2009. The detection of annual hypoxia in a low latitude freshwater reservoir in Kerala, India using the small AUV maya. Marine Technology Society Journal. 43 (3): 60-70.

Dhage, S.S., A. A. Dalvi \& D.V. Prabhu . 2012. Reaction kinetics and validity of BOD test for domestic wastewater released in marine ecosystems. Environment Assess. 184: 5301-5310.

Dinas Peternakan dan Perikanan Kabupaten Purwakarta. 2011. Buku Statistik Peternakan dan Perikanan Kabupaten Purwakarta: 51.

Effendi. H. 2003. Telaah Kualitas Air: Pengelolaan Sumberdaya Perairan dan Lingkungan. Penerbit Kanisius. Yogyakarta: 255 hlm.

Harsono, E. 2010. Evaluasi kemampuan pulih diri oksigen terlarut air Sungai Citarum hulu. Limnotek. 17 (1) : 1736.

Ji, Z.G. 2008. Hydrodynamics and Water Quality: Modelling Rivers, Lakes, and Estuaries. Wiley Interscience: 675.

Krismono. 1992. Hubungan antara tingkat trofik dengan populasi KJA mini di suatu badan air. Buletin Penelitian Perikanan Darat Balitbang Perikanan. 1: $45-50$.

Mc. Donald, M.E, Tikkanen, C. A, Axler, R. P, Larsen, C. P \& Host, G. 1996. Fish Simulation Culture Model (FIS-C): A Bioenergetics Based Model for Aquacultural Wasteload Application. Aquaculture Engineering. 15 (4) : 243 - 259.
Pena, M.A., S. Katsev, T. Oguz, \& D. gilbert. 2010. Modelling a dissolved oxygen dynamic and hypoxia. Biogeoscience. 7: 933-957.

Peraturan Pemerintah Republik Indonesia No 82 Tahun 2001 tentang Pengelolaan Kualitas air dan Pengendalian Pencemaran Air. Kementerian Lingkungan Hidup: 50.

Polli., B. 1994. Kajian konsep pengukuran BOD sebagai indicator pendugaan pencemaran bahan organik di perairan daerah tropis. Disertasi. IPB, Bogor: $80 \mathrm{hlm}$.

Salmin. 2005. Oksigen terlarut (DO) dan kebutuhan oksigen biologi (bod) sebagai salah satu indikator untuk menentukan kualitas perairan. Oseana. 30 (3): $21-26$.

Schierholz, E.L., J.S. Gulliver, S.C. Wilhelms \& H.E. Henneman. 2006. Gas Transfer from air diffusers. Water Research. 40: 1018 - 1026.

Simarmata, A.H. 2007 Kajian keterkaitan antara kemantapan cadangan oksigen dengan beban masukan bahan organik di Waduk Ir. H. Juanda Purwakarta, Jawa Barat. Disertasi. Sekolah Pasca Sarjana IPB, Bogor: 141.

Simarmata, A.H., E.M. Adiwilaga, B.W. Lay \& T. Partono. 2008. Kajian keterkaitan antara cadangan oksigen dan beban bahan organikdi zona lakustrin dan transisi Waduk Ir. H. Djuanda. Jurnal Penelitian Perikanan Indonesia. 14 (1): 1-14.

Singh, B. 2004. Determination of BOD kinetic parameters and evaluation of alternate methods. Thesis. Department Of Biotechnology \& Environmental Sciences. Thapar Institute Of Engineering \& Technology: 74.

Thang, V. Q., P. V. Quan., B. T. T Ha., \& N. T Thuy. 2005. Evaluation of biodegradation rate constant $(k)$ and BOD pollution in the lake system of Hanoi. Annual Report of FY 2004, The Core University Program between Japan Society for the Promotion of Science (JSPS) and Vietnamese Academy of Science and Technology (VAST). p. 115-119.

Tchobanoglous,G., F.L. Burton \& H.D.Stensel. 2003. Waste water engineering; Treatment and reuse. $4^{\text {th }}$ edition. Mc. Graw Hill. p 1818. 
Toufeek, M.A.F \& M. A. Korium. 2009. Physicochemical Characteristics of Water Quality in Lake Nasser Water. Global Journal of Environmental Research. 3 (3): 141-148.
Wetzel, R.G. 2001. Lymnology Lake and River Ecosystem Third Edition. Academic Press, California. p 1006. 